\title{
DISCURSOS SOBRE O EMPREENDEDORISMO: ENSINO PARA ENGENHARIA
}

DOI: 10.37702/2175-957X.COBENGE.2021.3371

Ricardo Luiz Perez Teixeira - ricardo.luiz@unifei.edu.br IEI Universidade Federal de Itajubá

Rua Irmã Ivone Drumond 200

35903-087 - Itabira - MG

Priscilla Chantal Duarte Silva - priscillachantal@unifei.edu.br ICPA Universidade Federal de Itajubá

Rua Irmã Ivone Drumond 200

35903-087 - Itabira - MG

Cynthia Helena Soares Bouças Teixeira - cyrilet@gmail.com CEGE FACE Universidade Federal de Minas Gerais

Av. Fleming 871

31310-490 - Belo Horizonte - MG

Resumo: O objetivo deste estudo é verificar como o empreendedorismo tem sido implantado na universidade pelos docentes. as experiências pedagógicas desses docentes são apresentadas neste trabalho na forma de relatos docentes acerca da forma de abordagem e implantação do empreendedorismo no ensino de engenharia. esses relatos docentes foram coletados por meio da técnica de entrevista de profundidade semiestruturada individual. os resultados apontam que, na visão docente, a formação do empreendedor supera a base instrutiva do egresso para êxito na abertura de uma empresa e na continuidade de um negócio.

Palavras-chave: Empreendedorismo; Educação Empreendedora, Métodos de Ensino; Perfis Discente e Docente 


\section{DISCURSOS SOBRE O EMPREENDEDORISMO: ENSINO PARA ENGENHARIA}

\section{INTRODUÇÃO}

A introdução do ensino do empreendedorismo nos currículos pode ter um impacto positivo tanto social quanto econômico, a partir do momento em que o egresso tem embasamento teórico e, de certo modo em sua formação prática, pela vivência em incubadora de empresas ou pelo contacto com o setor privado, para a criação de novas empresas ou negócios exitosos (DE CARVALHO ROCHA; FREITAS, 2014; LOPES; R., ALMEIDA; LIMA, 2019). Para tanto, o ensino do empreendedorismo deve oferecer uma aprendizagem ativa (prática) aos discentes que possibilitem a eles: (i) identificar, criar novos e melhores empreendimentos e negócios; (ii) um ferramental assertivo para o desenvolvimento e exploração sustentáveis; (iii) a criação de estratégias campeãs para a sobrevivência em um mercado de negócios dinâmico, agressivo, competitivo e globalizado (HENRIQUE; DA CUNHA, 2008; ARAÚJO SILVA; REATEGUI; DE OLIVEIRA, 2019).

\section{METODOLOGIA}

A característica metodológica deste estudo consiste na técnica de pesquisa qualitativa entrevista de profundidade, semiestruturada individual com 40 docentes que lecionam para diversos cursos de Engenharia, sendo que 12 desses docentes lecionam diretamente para o curso de Engenharia de Materiais e de Produção. A escolha da técnica se deve em função da liberdade atribuída ao entrevistado em expor suas opiniões sobre o tema "Empreendedorismo no Ensino de Engenharia" além da possibilidade de ampliação das respostas. Trata-se da realização de perguntas baseadas em um roteiro semiestruturado aos entrevistados. A escolha dos docentes para a entrevista se deu a partir de uma seleção de docentes que já tiveram alguma atuação com projetos ou ensino envolvendo empreendedorismo ou inovação. Esta pesquisa teve como objetivo levantar informações e reflexões docentes sobre as formas de desenvolvimento estabelecidas ou esperadas de empreendedorismo no ensino.

A escolha pela técnica qualitativa de entrevista em profundidade, no formato individual semiaberto e com questões semiestruturadas objetiva explorar o assunto Empreendedorismo no Ensino a partir da busca de informações, percepções e experiências dos docentes entrevistados (DUARTE, 2005). Na entrevista, procurou-se com um roteiro de 2 questões obter a intensidade nas respostas de cada docente sobre o assunto, sem buscar a quantificação ou representação estatística, para analisá-las e apresentá-las de forma estruturada (SOARES; DIEHL; VILVERT, 2016).

As perguntas na entrevista com profundidade foram três, são elas: questão 1- "Qual a sua expectativa ou vivência docente ou discente de empreendedorismo para engenharia?"; questão 2- "empreendedorismo já se encontra como componente na estrutura curricular do curso de engenharia ao qual você se encontra vinculado?". 


\section{ANÁLISE DOS DADOS ACERCA DA OPINIÃO DOCENTE SOBRE EMPREENDEDORISMO NO ENSINO, RESULTADOS E DISCUSSÕES}

As respostas das entrevistas em profundidade com os docentes apresentaram muitos pontos em comum, são eles: "há um forte vínculo entre o desenvolvimento socioeconômico e a cultura empreendedora"; "a cultura empreendedora é fortalecida quando se aborda o empreendedorismo no ensino, não somente como um componente curricular"; "quanto à estrutura curricular em empreendedorismo, há a necessidade de haver uma abordagem piloto de empreendedorismo em projetos práticos em conjunto às incubadoras de empresas ligadas à universidade pública e ao setor privado". Para os docentes que lecionam para o curso de engenharia de materiais e de produção (12 docentes), o ensino de empreendedorismo demandará uma abordagem mais prática orientada das demandas atuais e potenciais de inovação de produtos e processos em engenharia apresentados pela Indústria 4.0.

Das respostas à entrevista, destacamos 5 diferentes visões apresentadas pelos docentes para cada uma das perguntas. Os dados desses docentes foram ocultados por questões de sigilo e ética de pesquisa. Como categorização, as respostas foram elencadas e distinguidas por letras correspondentes a cada resposta dos docentes participantes da pesquisa. Utilizou-se a Análise do Discurso para auxiliar na interpretação das respostas. $\mathrm{Na}$ análise, as respostas foram estudadas individual e coletivamente usando o critério comparativo entre os informantes para verificar como o empreendedorismo tem sido implantado na universidade pelos docentes. As experiências pedagógicas desses docentes foram apresentadas neste trabalho na forma de relatos docentes.

\begin{tabular}{|l}
\hline Questão 1: Qual a sua expectativa ou vivência docente ou discente de \\
Empreendedorismo voltado para a Engenharia? \\
\hline Informante A: "Como expectativa vejo que deve ser discutido mais esse \\
tema com os professores das universidades porque são eles que irão \\
formar os alunos." \\
\hline Informante B: "A vivência é praticamente nula, uma vez que, na atual \\
matriz curricular das universidades no Brasil, sendo que tenho \\
experiência em ter lecionado em duas universidades particulares e uma \\
faculdade estadual em São Paulo, elas são extremamente conteudistas \\
dificultando a intercambialidade de disciplinas, habilidades e \\
competências e soma-se ao fato também das escolas superiores no \\
Brasil valorizar a pesquisa ao invés da formação acadêmica do \\
discente". \\
\hline Informante C: "Eu, como docente, não tenho vivência como \\
empreendedor, apenas sou filho de pais que foram comerciantes. (...) \\
Nesse tempo vi vários trabalhos que poderiam se tornar negócios, mas \\
não foram para a frente. Nesse ambiente de tecnologia de ponta e \\
acessível as pessoas parece ser um mundo extremamente interessante \\
para se empreender. Aqui no curso, estou tentando montar a primeira \\
Empresa Jr da universidade para fazer com que os alunos tenham um \\
primeiro contato nesse sentido. A partir daqui, pode-se ter a \\
possibilidade de se criar algo. (...) Sempre reforço nas aulas a \\
importância do empreendedorismo no mundo e cenários atuais."
\end{tabular}




\begin{tabular}{|l} 
fundamental para o enquadramento deste no mercado de trabalho, no \\
desenvolvimento de sua carreira e, por que não, para que tenha \\
melhores condições e parâmetros para identificar oportunidades, tomar \\
decisões e ter uma postura ativa como agente de uma comunidade."
\end{tabular}

$\mathrm{Na}$ visão da informante $\mathrm{A}$, observa-se que ela espera que o tema seja mais discutido no meio acadêmico, o que implica afirmar que não só é uma necessidade de que o empreendedorismo seja mais abordado, pois ainda não é muito trabalhado como enfoque de ensino, como também a visão do informante de que a preocupação do docente deve ser a formação. De fato, se não há discussão e preparação docente para o empreendedorismo nas universidades, não pode haver também formação empreendedora. Urge, nesse sentido, uma política de ensino voltada para esse fim. Em "porque são eles que irão formar os alunos", pode-se perceber que a formação do aluno coincide com a visão do professor sobre o papel do educador, isto é, a orientação de formar, no sentido de preparar o aluno para as exigências do mercado e formação profissional.

Para o informante $B$, a expectativa e a vivência não são positivas. $O$ informante ressalta a ideia de que as universidades não investem nesse tipo de ensino, isto é, são voltadas para um currículo conteudista, focado nas disciplinas técnicas e específicas. Com efeito, observa-se uma semelhança com o informante $A$, no sentido de reforçar a necessidade de mudança curricular nas universidades. Isso pode ser destacado por meio da análise da argumentação do discurso do informante $B$ ao dizer que as escolas superiores no Brasil valorizam a pesquisa ao invés da formação acadêmica do discente. Sob esse aspecto, o informante B alega que pesquisa e formação acadêmica são coisas distintas e que o empreendedorismo se enquadra melhor no segundo. $E$ indiretamente afirma que os currículos das universidades não estão preocupados com essa orientação metodológica. Pode-se observar também que a política de ensino ainda se centra no conteúdo das disciplinas específicas, sendo o Empreendedorismo algo complementar à formação. Contudo, uma vez que se espera do egresso das Engenharias que este tenha habilidades empreendedoras, faz-se necessário, pois, que as universidades voltem os seus currículos para a formação empreendedora, não só para o discente, mas com a preparação do próprio docente. Afinal, tendências apontam que a geração em formação consiste em uma geração sem emprego, voltada para profissões que desenvolvam seus próprios empregos e negócios. Gehringer (2008) destaca que a profissão do futuro é a de chefe. Em outros termos, o empreendedorismo deve fazer parte da formação curricular nas universidades.

O informante $C$ alega que, embora não tenha tido vivência como empreendedor, a sua experiência pessoal como filho de comerciantes e desenvolvimento de trabalhos com gestão fizeram com que obtivesse uma visão aberta sobre o empreendedorismo, sobretudo no que concerne à possibilidade de empreendimentos pela pesquisa, afirmando que "faziam várias pesquisas que poderia se tornar algum empreendimento se alguém animasse". Relata sua experiência em incentivos ao empreendedorismo e destaca pelo seu discurso que tem discutido no ensino de Engenharia a importância do empreendedorismo em: "Sempre reforço nas aulas a importância do empreendedorismo no mundo e cenários atuais." 
O informante $\mathrm{D}$ defende a ideia de que o empreendedorismo não é apenas para criar empresas, permite que o aluno tenha uma visão mais ampla sobre o mercado, na tomada de decisões e na postura ativa nas empresas, além da capacidade de identificar oportunidades. Assim como os demais informantes, ressalta a importância da implantação do empreendedorismo no ensino. Nesse contexto, pode-se observar que os docentes não estão 'preocupados com a possibilidade de implantação e abertura de novas empresas em si, mas com a formação do discente voltando-o para a política de ensino empreendedora, no que tange ao ensino das ferramentas que possibilitem uma educação com esse perfil.

Por último, o informante $E$ relaciona o empreendedorismo com a habilidade de autonomia e atribui a metodologia ativa a capacidade de favorecer a aprendizagem dessa habilidade. Smith (2005) lembra que o termo empreendedorismo está relacionado ao sujeito que assume a responsabilidade por algo referindo-se ao autoemprego ou a ocupação. $\mathrm{Na}$ visão do informante $E$, o termo pode ser usado também na vida pessoal quando se relaciona com a iniciativa. Com efeito, pode-se observar que todos os informantes consideram relevantes os estudos sobre empreendedorismo aplicado às engenharias pelo fato de esta trabalhar com a criação de produtos ou serviços, bem como resolução de problemas técnicos. E o empreendedorismo, como afirma Bryant (2015), consiste na identificação e exploração de novas oportunidades de valor, criação e captura, que podem ser não apenas em termos comerciais, mas também social, institucional ou cultural. Assim como enfatizado pelos informantes, sobretudo o informante $\mathrm{C}$, faz-se necessário rever a forma de ensino do empreendedorismo aprimorando como defende Bryant (2015) as habilidades empreendedoras a fim de que isso seja parte da formação do engenheiro. Como bem lembra o autor, o arquétipo da atividade empreendedora é a capacidade de criação a partir da visão de uma oportunidade tornando-a uma realidade de empreendimento, isto é, aproveitar a oportunidade a partir de uma visão de mercado, criando-se uma organização. Para isso, é necessário que o discente aprenda empreender e utilizar os recursos disponíveis.

\begin{tabular}{|l|l|}
\hline Questão 2: “Empreendedorismo" já se encontra como componente na \\
estrutura curricular do curso de engenharia ao qual você se encontra \\
vinculado? \\
\hline Informante A: "Sim, isolado numa disciplina do curso." \\
\hline Informante B: "O ensino de 'empreendedorismo' não está contemplado \\
na atual matriz curricular do curso que leciono as minhas aulas". \\
Informante C: "temos uma disciplina de Projetos. Nessa disciplina o \\
professor monta empresas e ensina a se fazer algum tipo de gestão, \\
mas não sei maiores detalhes." \\
Informante D: "Sim, se encontra". \\
\hline Informante E: "Ainda não, mas não acredito que todas as pessoas \\
sejam tão empreendedoras. (...) Acho então que não é qualquer pessoa \\
que consegue trabalhar essa disciplina, mas acima de tudo é preciso \\
ter pessoas que tenham de fato construído algo que seja empreendedor \\
e que possa mostrar o caminho das pedras para os estudantes."
\end{tabular}

Na questão 2, a maioria dos informantes alegam que o empreendedorismo não está presente na estrutura curricular do curso de Engenharia da instituição estudada. Encontrase isolada em uma disciplina e outra, mas nada articulado e plenamente definido como parte da política de ensino da Instituição, embora o empreendedorismo seja cobrado como uma capacidade e habilidade do egresso. Nesse sentido, observa-se que a instituição deveria repensar as formas de ensino do empreendedorismo já que este faz parte de um dos objetivos centrais da expectativa que se tem do egresso. $O$ informante $C$ é o que mais 
destaca a presença do ensino do empreendedorismo quando afirma que ele está presente na disciplina de Projetos e que esta orienta o discente para a gestão.

Já o informante $E$ relata a importância de o empreendedorismo ser ensinado a partir da experiência do próprio docente quando afirma "é preciso ter pessoas que tenham de fato construído algo que seja empreendedor e que possa mostrar o caminho das pedras para os estudantes". Nesse relato, pode-se observar que indiretamente o informante afirmou que se faz necessário ter tido alguma experiência com o empreendedorismo para este seja posteriormente ensinado. Ensinar o "caminho das pedras", como ressalta o informante E, consiste numa expressão metafórica clássica de representar o modo como se aprendeu, isto é, ensinar o que se sabe demonstrando o mesmo caminho de aprendizagem. De fato, é uma questão polêmica se é necessário ter criado algum empreendimento anteriormente para então ter a habilidade e capacidade de ensinar o empreendedorismo.

Criar uma mentalidade empreendedora, bem como voltar a formação científica para isso implica uma mudança de pensamento e na própria reformulação do currículo. A Universidade de um modo geral tem uma visão de formar o profissional para o mercado de trabalho com uma preocupação científica, no sentido de ensinar a Engenharia, no caso, com o perfil científico para que o discente tenha a preparação de buscar na Ciência por meio do conhecimento científico e da pesquisa científica as respostas e soluções para os mais diversos problemas.

Em outros contextos de outros cursos, não tem sido diferente, pois, em princípio, a Universidade tem o papel de fazer Ciência e busca se diferenciar do ensino tecnicista. $O$ que se acredita, nesse caso, é que a orientação do empreendedorismo seja rediscutida nas universidades. Se não é possível ter profissionais docentes com experiência em já ter sido empreendedor anteriormente com abertura de negócios, que se estimule a criação de empresas Júnior na Universidade, como lembrado pelo informante C, na primeira questão. Ademais, o empreendedorismo também pode ser estimulado com a mudança de concepção de que se formam os discentes somente para serem futuros empregados nas indústrias que precisam de engenheiros, mas de uma preparação de engenheiros para a inovação e a criação de empreendimentos. Shane e Venkataraman (2000) consideram que o empreendedorismo está atrelado tanto à percepção de oportunidades que podem ser transformadas em negócios lucrativos quanto à característica empreendedora. Esta última consiste na mudança de mentalidade e ao tipo de formação nas universidades.

Karim (2016) defende que criatividade e inovação são questões importantes no momento da identificação de oportunidades, sobretudo nas fases iniciais do processo de implantação do empreendedorismo e liderança, confiança e capacidade de gerenciamento de recursos nos últimos estágios. O autor orienta que essas habilidades devem ser preocupações constantes durante a formação em Engenharia. Desse modo, o empreendedorismo envolve junto com ele uma série de habilidades que devem ser coordenadas entre si para a formação do perfil empreendedor. Afinal, só é possível ter a visão de possibilidade de novos negócios quando se tem criatividade e inovação. Assim, todas as habilidades se complementam. Destaca-se que engenheiros com mentalidade empreendedora podem assumir papeis de liderança, tornando-se um intraempreendedor ou se tornar empresários abrindo o seu próprio negócio. Assume-se que muitos engenheiros acabam, infelizmente, aprendendo o empreendedorismo depois da graduação ou ainda por conta própria e não durante o curso. Logo, nota-se que não é uma abordagem para todos, muito menos uma preocupação das universidades. 


\section{CONSIDERAÇÕES FINAIS}

A entrevista em profundidade revela, pela análise do discurso dos informantes, que há uma consciência por parte dos docentes sobre a necessidade de reformulação ou adaptação das grades curriculares dos cursos de Engenharia para que estes voltem as políticas de ensino para a criação efetiva do perfil empreendedor ao longo do curso de Engenharia. Contudo, é notória a inexperiência dos docentes com o ensino do empreendedorismo, embora haja alguns esforços nesse sentido. O resultado do estudo aponta que a educação para o empreendedorismo deve ser incorporada aos programas acadêmicos das Engenharias. Nesse sentido, urge uma formação de Empreendedorismo aplicado às Engenharias para o profissional docente, para que este seja capaz de desenvolver a habilidade empreendedora nos discentes no âmbito das atividades acadêmicas.

\section{Agradecimentos}

Ao Instituto de Engenharias Integradas da Universidade Federal de Itajubá, ao grupo de pesquisa em metais Metals Group da Unifei, ao CEGE FACE UFMG e ao PPGEM UNIFEI MP.

\section{REFERÊNCIAS}

ARAÚJO SILVA, M. A. A de.; REATEGUI, B. A.; OLIVEIRA, C. B. Z. de. Características empreendedoras do discente do curso de Engenharia de Produção na Indústria 4.0. Revista Gestão em Análise, v. 8, n.1, p.150-163, 2019.

BRYANT, P.T. Entrepreneurship and Organizations. International Encyclopedia of the Social \& Behavioral Sciences, 2 ${ }^{\mathrm{a}}$ edição, v. 7, p.681-685, 2015. Disponível em: <http://dx.doi.org/10.1016/B978-0-08-097086-8.73006-6 681>. Acesso em: 28 dez 2019.

\section{DUARTE, J. Entrevista em profundidade. Métodos e técnicas de pesquisa em comunicação. São Paulo: Atlas, v.1, p. 62-83, 2005.}

GEHRINGER, M. Emprego de A a Z. São Paulo: Globo, 2008.

KARIM, M.S.A. Entrepreneurship education in an engineering curriculum. Procedia Economics and Finance, v. 35, p. 379-387, 2016.

LOPES, R.; ALMEIDA, M.; Lima, E. Desafios atuais e caminhos promissores para a pesquisa em empreendedorismo. Revista de Administração de Empresas, v. 59, n.4, p. 284-292, 2019.

ROCHA, E. L C. de.; FREITAS, A. A. F. Avaliação do ensino de empreendedorismo entre estudantes universitários por meio do perfil empreendedor. Revista de administração contemporânea, v.18, n.4, p. 465-486, 2014.

SHANE, S.; VENKATARAMAN, S. The promise of entrepreneurship as a field of research. Academy of Management Review, v. 25, n.1, p.217-226, 2000. 
SMITH, A. An inquiry into the nature and causes of the wealth of nations. State College: Jim Manis Editor, 2005.

SOARES, L.; DIEHL, E. E.; VILVERT, A. F. Módulo 6-Metodologia da pesquisa. UNASUS, 2016. Disponível em: <https://ares.unasus.gov.br/acervo/handle/ARES/3482>. Acesso em: 28 dez. 2019.

\section{DISCOURSES ON ENTREPRENEURSHIP: ENGINEERING TEACHING}

Abstract: The aim of this study is to verify how entrepreneurship has been implemented in the university by teachers. the pedagogical experiences of these teachers are presented in this paper in the form of teacher reports on the approach and implementation of entrepreneurship in engineering education. these teaching reports were collected through the technique of individual semi-structured depth interview. The results show that, in the teaching view, the formation of the entrepreneur goes beyond the instructional base of the egress for the success in the opening of a company and the continuity of a business.

Keywords: entrepreneurship, entrepreneurial education, teaching methods, student and teacher profiles. 